\title{
BaltDC: purification, characterization and infrared spectroscopy of an antiplatelet DC protein isolated from Bothrops alternatus snake venom
}

Mariana Santos Matias', Bruna Barbosa de Sousa ${ }^{1,8}$, Déborah Fernanda da Cunha Pereira ${ }^{1}$, Edigar Henrique Vaz Dias' ${ }^{1}$, Carla Cristine Neves Mamede ${ }^{2,8}$, Mayara Ribeiro de Queiroz ${ }^{8}$, Anielle Christine Almeida Silva ${ }^{4}$, Noelio Oliveira Dantas ${ }^{4}$, Andreimar Martins Soares ${ }^{5,6}$, Júnia de Oliveira Costa ${ }^{1,7^{*}}$ and Fábio de Oliveira ${ }^{3,8}$

\begin{abstract}
Background: Snake venoms are a complex mixture of proteins, organic and inorganic compounds. Some of these proteins, enzymatic or non-enzymatic ones, are able to interact with platelet receptors, causing hemostatic disorders. The possible therapeutic potential of toxins with antiplatelet properties may arouse interest in the pharmacological areas. The present study aimed to purify and characterize an antiplatelet DC protein from Bothrops alternatus snake venom.
\end{abstract}

Methods: The protein, called BaltDC (DC protein from B. alternatus snake venom), was purified by a combination of ion-exchange chromatography on DEAE-Sephacel column and gel filtration on Sephadex G-75. The molecular mass was estimated by polyacrylamide gel electrophoresis in the presence of sodium dodecyl sulfate (SDS-PAGE). The amino acid sequence of the $\mathrm{N}$-terminal region was carried out by Edman degradation method. Platelet aggregation assays were performed in human platelet-rich plasma (PRP). Infrared (IR) spectroscopy was used in order to elucidate the interactions between BaltDC and platelet membrane.

Results: BaltDC ran as a single protein band on SDS-PAGE and showed apparent molecular mass of $32 \mathrm{kDa}$ under reducing or non-reducing conditions. The $\mathrm{N}$-terminal region of the purified protein revealed the amino acid sequence IISPPVCGNELLEVGEECDCGTPENCQNECCDA, which showed identity with other snake venom metalloproteinases (SVMPs). BaltDC was devoid of proteolytic, hemorrhagic, defibrinating or coagulant activities, but it showed a specific inhibitory effect on platelet aggregation induced by ristocetin and epinephrine in PRP. IR analysis spectra strongly suggests that $\mathrm{PO}_{3}^{2-}$ groups, present in BaltDC, form hydrogen bonds with the $\mathrm{PO}_{2}^{-}$groups present in the non-lipid portion of the membrane platelets.

Conclusions: BaltDC may be of medical interest since it was able to inhibit platelet aggregation.

Keywords: Snake venom, Bothrops alternatus, DC protein, Platelet aggregation

\footnotetext{
* Correspondence: juniacosta@iftm.edu.br

${ }^{1}$ Postgraduate Program in Genetics and Biochemistry, Institute of Genetics and Biochemistry, Federal University of Uberlândia (UFU), Uberlândia, MG, Brazil

${ }^{7}$ Federal Institute of Education, Science and Technology of Triângulo Mineiro (IFTM), Campus Ituiutaba, Ituiutaba, MG, Brazil

Full list of author information is available at the end of the article
} 


\section{Background}

Isolation and characterization of pharmacologically active compounds present in snake venoms have been the focus of numerous scientific research studies. Approximately $90 \%$ of snake venom dry weight is constituted of protein components, including peptides and enzymes. The non-protein fraction of the venom is composed by low-mass organic molecules, such as carbohydrates, lipids, free amino acids and inorganic compounds including calcium, phosphorus, magnesium, potassium, sodium and zinc $[1,2]$.

Snake venoms are rich sources of metalloproteinases, a group of enzymes that are the primary factors responsible for hemorrhage and may also interfere with the hemostatic system [3-6]. Snake venom metalloproteinases (SVMPs) have been classified into three classes, from PI to PIII, according to their multi-domain structure [7]. The PIII SVMPs are the largest among all the classes of metalloproteinases. They are composed of an $\mathrm{N}$-terminal metalloproteinase domain, a disintegrin-like domain (D) and a Cys-rich C-terminus (C). PIII SVMPs may undergo proteolytic processing, releasing the catalytic domain (metalloproteinases) [7]. D and C domains are linked by disulfide bonds, so they are released as a unique molecule (DC protein). This molecule is able to interact with integrins present on the cell surface and may trigger numerous cellular processes such as platelet aggregation; angiogenesis; metastasis; tumor growth; adhesion, migration and proliferation of cells [8-12].

In this work, we describe the purification, characterization and IR spectra of an antiplatelet DC protein, called BaltDC, isolated from $B$. alternatus snake venom.

\section{Methods}

\section{B. alternatus snake venom}

Desiccated B. alternatus snake venom was purchased from Bioagents Serpentarium (Brazil). This serpentarium is registered in the Brazilian Institute of Environment and Renewable Natural Resources (IBAMA - n. 471,301). The crude venom was dried in a vacuum desiccator at room temperature immediately after milking and then stored at $-20{ }^{\circ} \mathrm{C}$.

\section{Animals}

Swiss male mice (20-25 g) were provided by the Center of Animal Facilities and Animal Experimentation (CEBEA) of the Federal University of Uberlândia (Uberlândia, MG, Brazil). The animals were maintained under conditions of controlled temperature $\left(22 \pm 2{ }^{\circ} \mathrm{C}\right)$ and 12-h light/dark cycles with free access to food and water. The experimental protocol was approved by the Committee for Ethics in Animal Experimentation of the Federal University of Uberlândia (CEUA/UFU, protocol number 108/12).

\section{Human blood}

Human blood was obtained by means of donation from volunteers. The criteria for selection of donors were: be in good state of health, have 18 to 65 years old, weighting at least $50 \mathrm{~kg}$, no use of any medication that interferes with hemostasis, no use of illicit drugs and no alcohol consumption for at least $24 \mathrm{~h}$ before donation. The experiments were carried out according to the current guidelines for research with humans established by the Committee for Ethics in Human of the Federal University of Uberlândia (CEP/UFU - protocol number 1.627.982/2016).

\section{Isolation of BaltDC}

B. alternatus crude venom (300 $\mathrm{mg}$ ) was dissolved in $2.0 \mathrm{~mL}$ of $0.05 \mathrm{M}$ ammonium bicarbonate buffer $(\mathrm{pH} 7.8)$ and applied to a DEAE-Sephacel column $(2.5 \times 20 \mathrm{~cm})$. The samples were eluted using a linear gradient $(0.05-$ $1.0 \mathrm{M}$ ) of the same buffer. The ninth peak was pooled, lyophilized and applied to a Sephadex G-75 column $(1.0 \times 100 \mathrm{~cm})$ previously equilibrated with $0.05 \mathrm{M}$ ammonium bicarbonate buffer $(\mathrm{pH}$ 7.8). All peaks were monitored by measuring absorbance at $280 \mathrm{~nm}$ on a spectrophotometer BioSpec-Mini (Shimadzu Biotech, Japan) at a flow rate of $20 \mathrm{~mL} / \mathrm{h}$ and fractions of $3.0 \mathrm{~mL} /$ tube were collected. The purified protein was named BaltDC. To confirm the degree of purity, BaltDC was submitted to reverse-phase Source 15RPC ST column $(4.6 \times 100 \mathrm{~mm})$ using the ÄKTApurifier ${ }^{\text {Ts }}$ HPLC system. The column was equilibrated with $0.1 \%$ trifluoroacetic acid (solvent $\mathrm{A}$ ) and eluted with a linear concentration gradient from 0 to $100 \%$ of $70 \%$ acetonitrile, $0.1 \%$ trifluoroacetic acid (solvent B) at a flow rate of $0.3 \mathrm{~mL} / \mathrm{min}$. Absorbance was monitored at $280 \mathrm{~nm}$.

\section{Estimation of protein concentration}

Protein concentration was determined by the method previously described by Bradford [13], using bovine serum albumin as standard.

\section{Electrophoretic analysis}

Polyacrylamide gel electrophoresis in the presence of sodium dodecyl sulfate (SDS-PAGE) was performed as described by Laemmli [14] using 14\% $(w / v)$ gels. Electrophoresis was carried out at $20 \mathrm{~mA} /$ gel in Tris-glycine buffer (pH 8.3) containing 0.01\% SDS. The molecular mass standard proteins used were phosphorylase $b$ (97 kDa), bovine serum albumin $(66 \mathrm{kDa})$, ovalbumin (45 kDa), carbonic anhydrase (30 kDa), soybean trypsin inhibitor $(20.1 \mathrm{kDa})$ and $\alpha$-lactalbumin $(14.4 \mathrm{kDa})$. Gels were stained with Coomassie blue R-250, 0.2\% (w/v). 


\section{$\mathrm{N}$-terminal sequencing}

A PPSQ-33A (Shimadzu) automated sequencer was used for the N-terminal sequencing according to the methodology described by Rodrigues et al. [15]. The identity of the primary sequence of BaltDC, compared with other proteins, was evaluated using BLAST (http://blast.ncbi.nlm.nih.gov/Blast.cgi).

\section{Platelet aggregation assay}

Platelet aggregation assays were performed in PRP and measured using the automated Aggregometer 4 channels (AggRAMTM version 1.1, Helena Laboratories, USA) as described by Queiroz et al. [16]. Human blood, collected in the presence of sodium citrate (3.2\%), was centrifuged at $100 \times g$ for $12 \mathrm{~min}$ at room temperature to obtain PRP. Platelet-poor plasma (PPP) was obtained from the residue by centrifugation of citrated blood at $1000 \times \mathrm{g}$ for $15 \mathrm{~min}$. Assays were carried out using $200 \mu \mathrm{L}$ of PRP maintained at $37^{\circ} \mathrm{C}$ under continuous stirring in siliconized glass cuvettes. Aggregation was triggered with collagen $(10 \mu \mathrm{g} / \mathrm{mL})$, ADP $(20 \mu \mathrm{M})$, ristocetin $(1.5 \mathrm{mg} / \mathrm{mL})$ or epinephrine $(300 \mu \mathrm{M})$ with BaltDC $(20,40$ and $80 \mu \mathrm{g})$. One hundred percent $(100 \%)$ aggregation was expressed as the percentage absorbance relative to PPP aggregation. Control experiments were performed using only platelet agonists. All experiments were carried out in triplicate.

\section{Infrared spectra}

IR spectra of the samples were recorded at room temperature using a Shimadzu Fourier Transform IR (FT-IR) spectrophotometer (Vertex 70, Bruker Optik) in the spectral range 440 to $4000 \mathrm{~cm}^{-1}$ via a total attenuated reflectance element coupled (ATR) with resolution of $2 \mathrm{~cm}^{-1}$.

\section{Results and discussion}

In Brazil, the $B$. alternatus snake, popularly known as urutu cruzeiro or cruzeira, is found in swamps, marshes and other humid local. It is also commonly found in sugarcane plantations [17]. In this work, we described the purification (chromatographic steps), electrophoretic profile, N-terminal sequence and IR spectra of an antiplatelet DC protein from this snake venom. The protein was isolated by only two steps of purification (ion-exchange and gel filtration chromatography). B. alternatus crude venom $(300 \mathrm{mg})$ was applied on a DEAE-Sephacel column and produced ten main protein peaks (Fig. 1a). The ninth peak was further fractionated by size exclusion chromatography (Sephadex G- 75), resulting in three main peaks (Fig. 1b). The second peak of this chromatography, which was named BaltDC, was devoid of proteolytic, hemorrhagic, defibrinating or coagulant

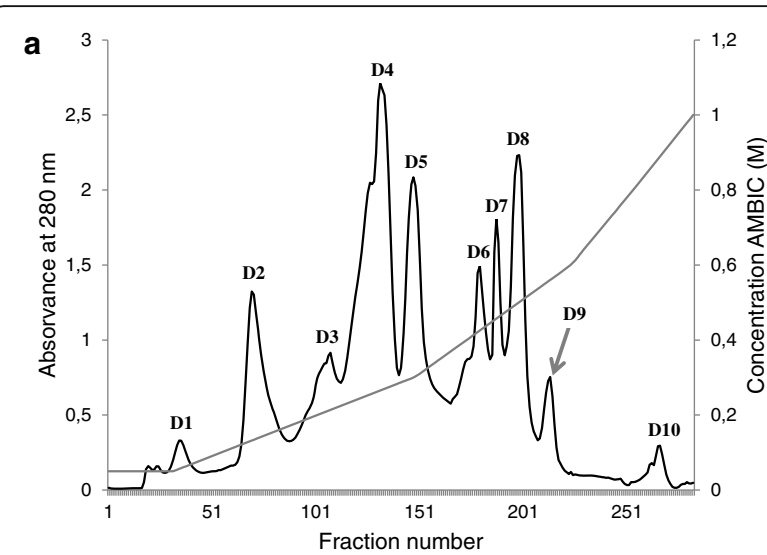

b

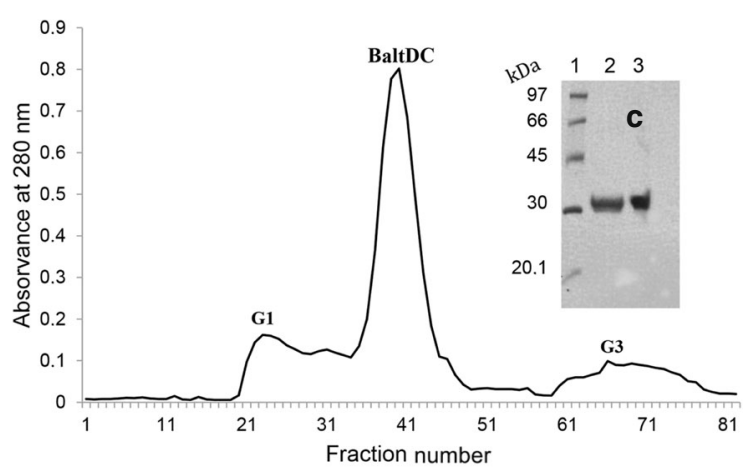

d

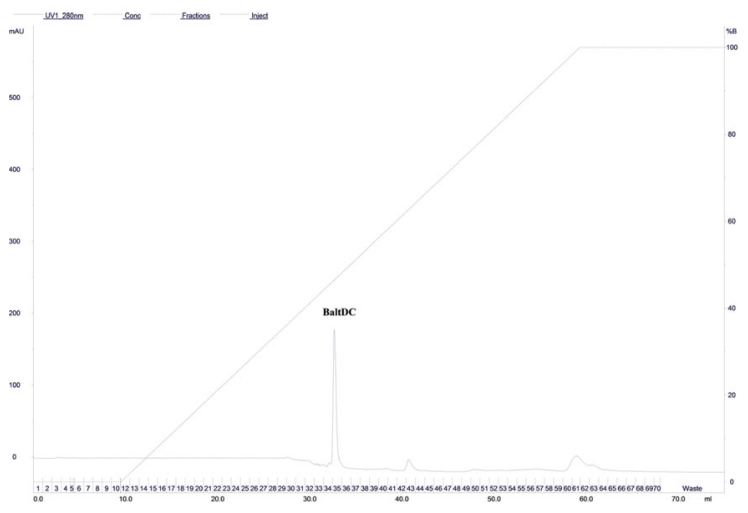

Fig. 1 Purification of BaltDC.(a) Anion-exchange chromatography of B. alternatus crude venom on a DEAE-Sephacel column $(2.5 \times 20 \mathrm{~cm})$ equilibrated with $0.05 \mathrm{M}$ ammonium bicarbonate ( $\mathrm{pH} 7.8)$ and eluted with a convex concentration gradient of the same buffer $(0.05-1 \mathrm{M})$. (b) Gel filtration on Sephadex G-75 column $(1.0 \times 100 \mathrm{~cm})$ : ninth peak was applied to the column and eluted with $0.05 \mathrm{M}$ ammonium bicarbonate. Fractions of $3.0 \mathrm{~mL} /$ tube were collected and the absorbance was read at $280 \mathrm{~nm}$. (c) SDS-PAGE: Lane 1 - standard proteins; lane 2 - BaltDC under non-reducing conditions; lane 3 BaltDC under reducing conditions. The molecular mass standard proteins used were phosphorylase b (97 kDa), bovine serum albumin (66 kDa), ovalbumin (45 kDa), carbonic anhydrase (30 kDa) and soybean trypsin inhibitor (20.1 kDa). Gels were stained with Coomassie blue R-250, 0.2\%. (d) Reverse-phase HPLC on a Source 15RPC ST column $(4.6 \times 100 \mathrm{~mm})$ equilibrated with $0.1 \%$ trifluoroacetic acid (TFA) and eluted with a linear concentration gradient from 0 to $100 \%$ of solution B (70\% acetonitrile in $0.1 \%$ TFA) 


\begin{tabular}{|c|c|c|c|c|c|c|c|c|c|}
\hline \multirow{3}{*}{ Majority } & \multicolumn{9}{|c|}{ TDIISPPVCGNELLEVGEECDCGTPENCQNECCDAATCKLKSGS $Q C$ CGHGDCCEQCKFSKSGTECRASMSECDPAEHCTGQ } \\
\hline & 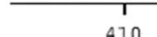 & 19 & 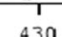 & 1 & 15 & 19 & 1 & 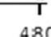 & \\
\hline & 410 & 420 & 430 & 440 & 350 & 460 & 470 & 486 & \\
\hline & \multicolumn{9}{|c|}{--IISPPVCENELLLEVGEECDDCGIPENCUNECCDA } \\
\hline Leucurogin & \multicolumn{9}{|c|}{ TDIISPPVCGNELLEVGEECDCGTPENCQNECCDA } \\
\hline Jararhagin-C & \multirow{2}{*}{\multicolumn{9}{|c|}{ 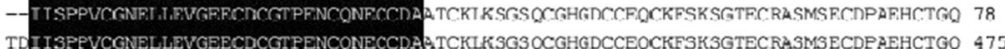 }} \\
\hline VAP2A & \multirow{2}{*}{\multicolumn{9}{|c|}{ 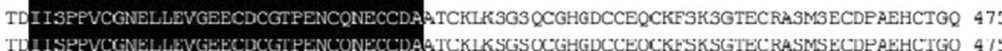 }} \\
\hline WMP-III & & & & & & & & & \\
\hline Jararhagin & \multicolumn{9}{|c|}{ TDIISPPVCGNSLLLVGEECDCGTPENCONECCDA } \\
\hline VAP2B & \multirow{2}{*}{\multicolumn{9}{|c|}{ TLIISPPUCGNSLLLVGEECDCGTPENCQNECCDA2 }} \\
\hline BITM06A & \multirow{2}{*}{\multicolumn{9}{|c|}{ 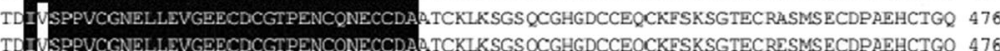 }} \\
\hline Brevilysin $\mathrm{H} 6$ & & & & TCKL & GHGDC & & SMSE & $A C T G Q$ & 476 \\
\hline Bothropasin & & & & & & & SMSEC & & 478 \\
\hline
\end{tabular}

Fig. 2 Sequence alignment of BaltDC and members of the PIII SVMPs: jararhagin-C (AAB30855.1), leucurogin (P0DJ87.1), VAP2A (A4PBQ9.1), VMPIII (C9E1R8.1), jararhagin (P30431.1), VAP2B (Q90282.1), BITM06A (Q8QG88.1), brevilysin-H6 (P0C7B0.2) and bothropasin (O93523.2). The conserved residues are shown in black. The alignment and figure were generated and evaluated using BLAST (http://blast.ncbi.nlm.nih.gov/Blast.cgi)

activities (data not shown), but it is able to interfere on platelet aggregation.

Electrophoretic (SDS-PAGE) analysis under denaturing and reducing conditions indicated that BaltDC had an apparent molecular mass of $32 \mathrm{kDa}$ (Fig. 1c). The high degree of purity of BaltDC was confirmed by reversephase HPLC chromatography on a Source 15RPC ST column, revealing a unique major peak (Fig. 1d). Comparison of the N-terminal sequence of BaltDC (IISPPVCGNELLE
VGEECDCGTPENCQNECCDA) showed similarity with other PIII SVMPs from Bothrops genus. The N-terminal of BaltDC is similar to the middle of others metalloproteinases skipping the catalytic domain such as leucurogin, jararhagin-C, VAP2A, VMP-III, jararhagin, bothropasin and others (Fig. 2) [18-23].

The PIII SVMPs are high molecular mass proteins that have a proteinase domain followed by disintegrin-like (D) and cysteine-rich (C) domains. Jia et al. [24] and

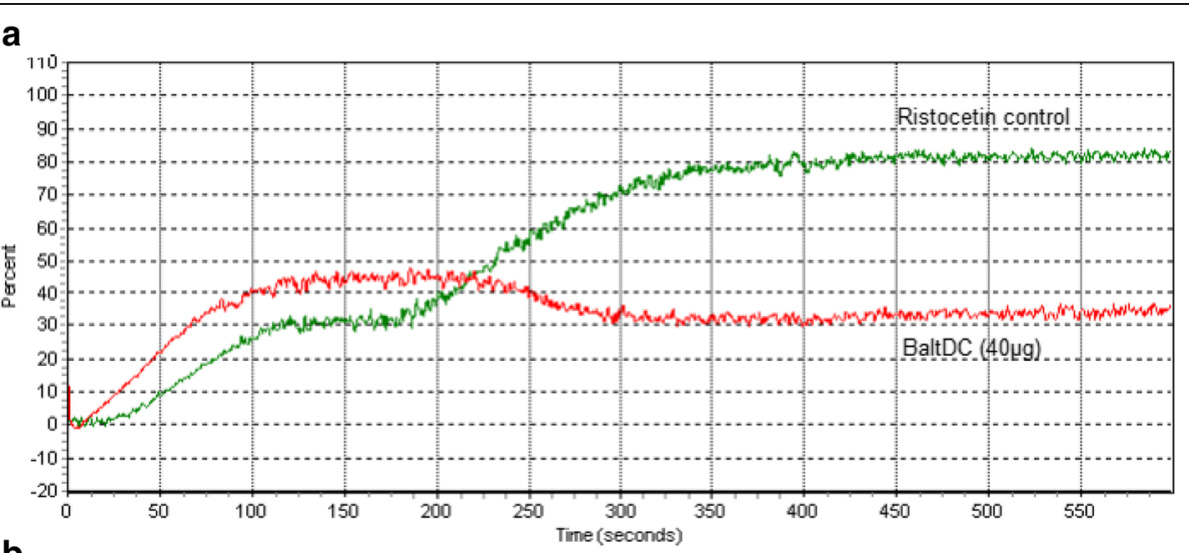

b

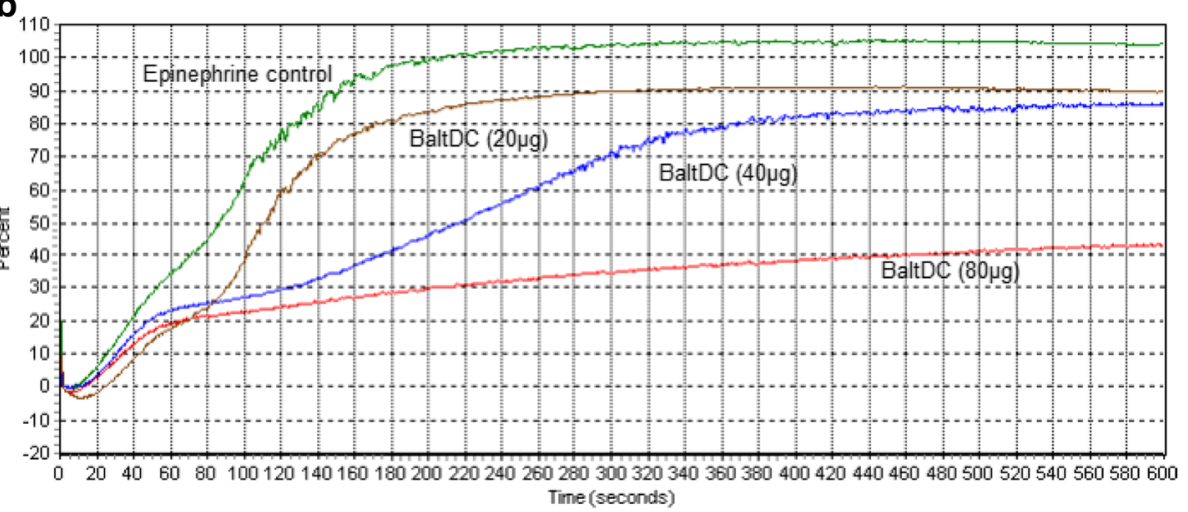

Fig. 3 Effect of BaltDC on (a) ristocetin and (b) epinephrine-induced platelet aggregation. PRP was preincubated with BaltDC for 30 min at $37^{\circ} \mathrm{C}$ before adding agonists. Platelet aggregation was recorded for $10 \mathrm{~min}$ in an AggRAM platelet aggregation system with four-channel laser optics (Helena Laboratories, EUA). Results were expressed as an increase in light transmission. Control experiments were performed using only platelet agonists 
Serrano et al. [25] reported the hypothesis that the DC domain contributes to the proteolytic specificity of PIII SVMPs, since it is targeted to bind to critical protein substrates. On the other hand, studies with synthetic peptides, such as the one by Pinto et al. [26], suggest that the $\mathrm{C}$ domain of the jararhagin binds to vWF. According to Fox and Serrano [27], some proteinases from snake venom may generate biologically active intact polypeptides of approximately $30 \mathrm{kDa}$ that correspond to the DC protein, which may be released from their precursor forms by proteolytic processing.

Brevilysin-H6, bothropasin, leucurolysin B and jararhagin are PIII SVMPs composed of a metalloproteinase domain associated with a DC domain, which may be released from auto-proteolytic events $[5,22,23,28]$. BaltDC is similar to jararhagin $\mathrm{C}(28 \mathrm{kDa})$, acucetin $(30 \mathrm{kDa})$ and alternagin-C $(29 \mathrm{kDa})$, which are $\mathrm{DC}$ proteins released through auto-proteolysis from $B$. jararaca,
$A$. acutus and $B$. alternatus, respectively $[12,19,29]$. As jararhagin $C$, acutin and alternagin- $C$, BaltDC has no enzymatic activity. These results associated with the $\mathrm{N}$ terminal sequence leads us to believe that the BaltDC may be a fragment of class PIII SVMPs, in which the DC domain was processed from proteinase domain, as proposed by Fox and Serrano [7].

DC proteins are known to bind to different platelet integrins that mediate platelet aggregation. A number of DC proteins have been used in the studies of modulators of platelet adhesion receptors and their ligands $[12,30,31]$. In this work, we characterized the interference of BaltDC on platelet aggregation using collagen, ADP, epinephrine and ristocetin as agonist. Our results showed that $40 \mu \mathrm{g}$ and $80 \mu \mathrm{g}$ of BaltDC was able to inhibit approximately $60 \%$ of platelet aggregation induced by ristocetin and epinephrine, respectively (Fig. 3a and b). On the other hand, BaltDC had little or

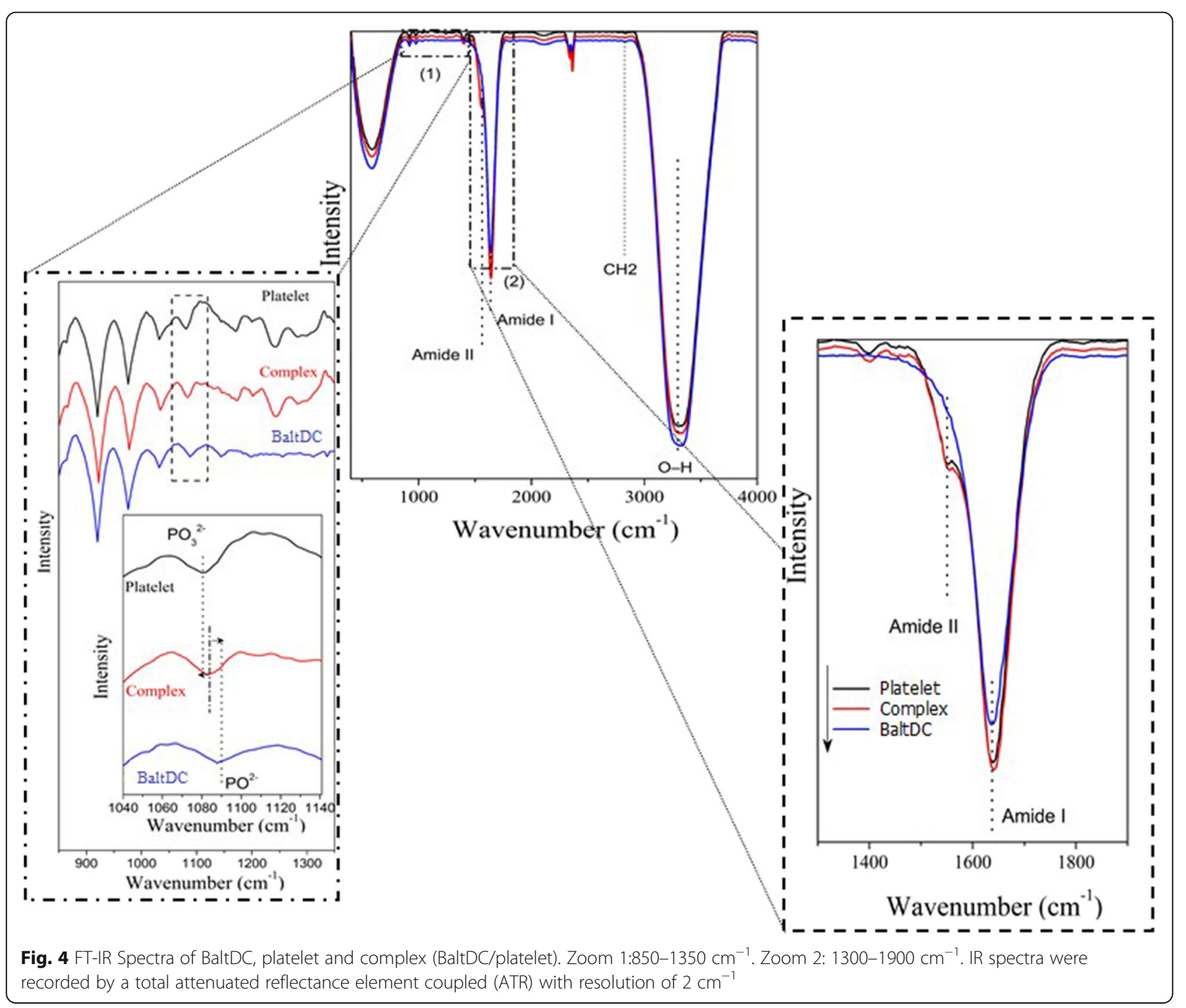


no effect on platelet aggregation induced by collagen or ADP (data not shown). These results suggest that BaltDC inhibits platelet aggregation by a possible common pathway for ristocetin and epinephrine. Another PIII SVMPs, such as acurhagin, purified from the venom of Agkistrodon acutus, also inhibits the ristocetin-induced platelet aggregation by hydrolyzing the vWF [32]. Our results strongly suggest that BaltDC inhibits platelet aggregation by preventing the binding of vWF and epinephrine to their respective receptors since it does not have a catalytic effect. Probably, BaltDC does not interact with the $\alpha \operatorname{Ilb} \beta 3, \alpha \mathrm{V} \beta 3$ or $\alpha 2 \beta 1 \mathrm{x}$ integrins since it does not inhibit the aggregation induced by ADP or collagen. However, more data are needed to elucidate the mechanism of action of BaltDC.

Here, we also show some results that may contribute to the understanding of a type of interaction that occurs between BaltDC and the platelet membrane. In order to elucidate these interactions, we used the IR spectroscopy. This methodology is not invasive and it has been used as an extremely useful tool for the investigation of interactions between lipids and proteins and other biological and biomedical studies [33-38].

Fig. 4 shows the FT-IR spectra of BaltDC and platelet alone and when they are complexed. In the region 850$1350 \mathrm{~cm}^{-1}$ (zoom 1), we observed a variety of characteristic IR group frequencies similar in all spectra. This same figure shows that the spectrum of BaltDC has a band at $1087 \mathrm{~cm}^{-1}$ while the spectrum of platelet has a band at $1080 \mathrm{~cm}^{-1}$, which are characteristics of $\mathrm{PO}_{2}^{-}$and $\mathrm{PO}_{3}{ }^{2-}$ symmetric stretching vibrations, respectively $[39,40]$. Interestingly, the spectrum of BaltDC/platelet complex showed a band at $1083 \mathrm{~cm}^{-1}$, which presented a change of the frequencies relative to the spectra of BaltDC and platelet, when they are separated. These results support the hypothesis that the $\mathrm{PO}_{3}^{2-}$ groups, present in BaltDC, make hydrogen bonds with the $\mathrm{PO}_{2}^{-}$groups present on the non-lipid portion of the membrane platelets [41-43]. We believe that the $\mathrm{PO}_{2}^{-}$groups are part of protein complexes, which are buried in the lipid bilayer since these groups are not commonly found in the plasma membrane. In addition, no changes were observed in the characteristic spectral bands of phosphate groups generally found in the membrane phospholipids [44].

In the region 1300-1900 $\mathrm{cm}^{-1}$ (zoom 2), we observed in both FT-IR spectra, BaltDC and platelets, a band at $1640 \mathrm{~cm}^{-1}$, located in amide I region, which indicates $\alpha$ helical conformation $[38,45]$. The spectrum of protein /platelet complex shows that the bands corresponding to amide I and II regions remained unchanged. These results suggest that the interaction between BaltDC and platelets causes no conformational changes in membrane, prevailing the $\alpha$-helix structure [46]. These findings support the hypothesis that BaltDC does not act catalytically and therefore it could act as an antagonist of the ristocetin and epinephrine receptors.

\section{Conclusions}

We presented the purification, characterization and IR spectrum of BaltDC, a DC protein $(32 \mathrm{kDa})$ originated from autolysis of a PIII SVMPs from B. alternatus snake venom. This protein was able to inhibit platelet aggregation induced by ristocetin and epinephrine and, therefore, it may be of medical interest as a novel therapeutic antiplatelet agent.

\section{Abbreviations}

BaltDC: DC protein isolated from Bothrops alternatus snake venom; DC protein: D (disintegrin-like) and C (Cys-rich C-terminus) domains are released as a unique molecule; HPLC: High performance liquid chromatography; IR: Infrared; PPP: Platelet-poor plasma; PRP: Platelet-rich plasma; SDS-

PAGE: Polyacrylamide gel electrophoresis in the presence of sodium dodecyl sulfate; SVMP: Snake venom metalloproteinase

\section{Acknowledgements}

The authors gratefully acknowledge the support of the Federal University of Uberlândia, Uberlândia, MG, Brazil, and would like to thank the Program for Technological Development in Tools for Health-PDTIS-FIOCRUZ for the use of its facilities. Thanks are also due to the Center for the Study of Venoms and Venomous Animals (CEVAP) of UNESP for enabling the publication of this paper (Edital Toxinologia CAPES no. 063/2010, Process no. 230.38.006285/2011-21, AUXPE Toxinologia 1219/2011).

\section{Funding}

This work was supported by the State of Minas Gerais Research Foundation (FAPEMIG), National Council for Scientific and Technological Development (CNPq), Coordination for the Improvement of Higher Education Personnel (CAPES), Ministry of Science and Technology (MCT) of Brazil, National Institute of Science and Technology on Toxins (INCTTOX), Funding Authority for Studies and Projects (FINEP), Rondônia Foundation for the Support to the Development of Scientific and Technological Actions, and the State of Rondônia Research Foundation (FAPERO), Brazil.

Availability of data and materials

The datasets used and/or analyzed during the current study are available from the first author (MMS) on reasonable request.

\section{Authors' contributions}

MSM, BBS, DFCP, EHVD, CCNM and MRQ performed the experiments. ACAS and NOD performed the infrared experiments. AMS performed the N-terminal sequence. JOC participated in the analysis and discussion of the results and performed a critical revision of the work. FO was responsible for the design of the work and supervised all experiments. All authors contributed to writing of this manuscript and approved the final version.

\section{Ethics approval and consent to participate}

The experimental protocol involving animals was approved by the Committee for Ethics in Animal Experimentation of the Federal University of Uberlândia (CEUA/UFU), Minas Gerais, Brazil (protocol number 108/12). The experiments were also performed in accordance with the current guidelines for research with humans, established by the Committee for Ethics in Human Research of Federal University of Uberlândia (CEP/UFU), Minas Gerais, Brazil (protocol number 1.627.982/2016).

Consent for publication Not applicable.

Competing interests

The authors declare that they no competing interests. 


\section{Publisher's Note}

Springer Nature remains neutral with regard to jurisdictional claims in published maps and institutional affiliations.

\begin{abstract}
Author details
${ }^{1}$ Postgraduate Program in Genetics and Biochemistry, Institute of Genetics and Biochemistry, Federal University of Uberlândia (UFU), Uberlândia, MG, Brazil. ${ }^{2}$ Institute of Agricultural Sciences, Federal University of Uberlândia (UFU), Monte Carmelo, MG, Brazil. Institute of Biomedical Sciences, Federal University of Uberlândia (UFU), Uberlândia, MG, Brazil. ${ }^{4}$ Institute of Physics, Federal University of Uberlândia (UFU), Uberlândia, MG, Brazil. ${ }^{5}$ Center for the Study of Biomolecules Applied to Health (CEBio), Oswaldo Cruz Foundation (Fiocruz - Rondônia) and Health Group, Federal University of Rondônia (UNIR), Porto Velho, RO, Brazil. ' University Center São Lucas (UniSL), Porto Velho, RO, Brazil. ${ }^{7}$ Federal Institute of Education, Science and Technology of Triângulo Mineiro (IFTM), Campus Ituiutaba, Ituiutaba, MG, Brazil. ${ }^{8}$ National Institute of Science and Technology in Nanobiopharmaceutics (N-Biofar), Belo Horizonte, MG, Brazil.
\end{abstract}

\section{Received: 27 March 2017 Accepted: 12 July 2017}

Published online: 28 July 2017

\section{References}

1. Markland FS. Snake venoms and the hemostatic system. Toxicon. 1998; 36(12):1749-800.

2. Matsui T, Fujimura Y, Titani K. Snake venom proteases affecting hemostasis and thrombosis. Biochim Biophys Acta. 2000;1477(1-2):146-56.

3. Gay CC, Maruñak SL, Teibler P, Ruiz R, Acosta de Pérez OC, Leiva LC. Systemic alterations induced by a Bothrops alternatus hemorrhagic metalloproteinase (baltergin) in mice. Toxicon. 2009;53(1):53-9.

4. Girón ME, Guerrero B, Salazar AM, Sánchez EE, Alvarez M, Rodríguez-Acosta A. Functional characterization of fibrinolytic metalloproteinases (colombienases) isolated from Bothrops colombiensis venom. Toxicon. 2013;74:116-26.

5. Sanchez EF, Gabriel LM, Gontijo S, Gremski LH, Veiga SS, Evangelista KS, et al. Structural and functional characterization of a P-III metalloproteinase, leucurolysin-B, from Bothrops leucurus venom. Arch Biochem Biophys. 2007; 468(2):193-204.

6. Sanchez EF, Richardson M, Gremski LH, Veiga SS, Yarleque A, Niland S, et al. A novel fibrinolytic metalloproteinase, barnettlysin-I from Bothrops barnetti (Barnett's pitviper) snake venom with anti-platelet properties. Biochim Biophys Acta. 2016;1860(3):542-56.

7. Fox JW, Serrano SM. Insights into and speculations about snake venom metalloproteinase (SVMP) synthesis, folding and disulfide bond formation and their contribution to venom complexity. FEBS J. 2008;275(12):3016-30.

8. Limam I, Bazaa A, Srairi-Abid N, Taboubi S, Jebali J, Zouari-Kessentini R, et al. Leberagin-C, A disintegrin-like/cysteine-rich protein from Macrovipera lebetina transmediterranea venom, inhibits alphavbeta3 integrin-mediated cell adhesion. Matrix Biol. 2010;29(2):117-26.

9. Menezes MC, de Oliveira AK, Melo RL, Lopes-Ferreira M, Rioli V, Balan A, et al. Disintegrin-like/cysteine-rich domains of the reprolysin HF3: Site-directed mutagenesis reveals essential role of specific residues. Biochimie. 2011;93(2): 345-51.

10. Ramos $\mathrm{OH}$, Terruggi $\mathrm{CH}$, Ribeiro JU, Cominetti MR, Figueiredo CC, Bérard M, et al. Modulation of in vitro and in vivo angiogenesis by alternagin- $\mathrm{C}$, a disintegrin-like protein from Bothrops alternatus snake venom and by a peptide derived from its sequence. Arch Biochem Biophys. 2007:461(1):1-6.

11. Sant'Ana EM, Gouvêa CM, Nakaie CR, Selistre-de-Araújo HS. Angiogenesis and growth factor modulation induced by alternagin $C$, a snake venom disintegrin-like, cysteine-rich protein on a rat skin wound model. Arch Biochem Biophys. 2008;479(1):20-7.

12. Selistre-de-Araujo HS, Cominetti MR, Terruggi CHB, Mariano-Oliveira A, de Freitas MS, Crepin M, et al. Alternagin-C, a disintegrin-like protein from the venom of Bothrops alternatus, modulates a 2 B1 integrin-mediated cell adhesion, migration and proliferation. Braz J Med Biol Res. 2005;38(10):1505-11.

13. Bradford MM. A rapid and sensitive method for the quantitation of microgram quantities of protein utilizing the principle of protein-dye binding. Anal Biochem. 1976;72:248-54.

14. Laemmli UK. Cleavage of structural proteins during the assembly of the head of bacteriophage T4. Nature. 1970;227(5259):680-5.

15. Rodrigues RS, Izidoro LF, Teixeira SS, Silveira LB, Hamaguchi A, HomsiBrandeburgo $\mathrm{Ml}$, et al. Isolation and functional characterization of a new myotoxic acidic phospholipase A(2) from Bothrops pauloensis snake venom. Toxicon. 2007;50(1):153-65.

16. Queiroz MR, Mamede CCN, Fonseca KC, de Morais NCG, de Sousa BB, SantosFilho NA, et al. Rapid purification of a new P-I class metalloproteinase from Bothrops moojeni venom with antiplatelet activity. Biomed Res Int. 2014;2014: 352420. doi:10.1155/2014/352420.

17. Campbell JA, Lamar WW. The venomous reptiles of the Western Hemisphere. Ithaca: Comstock Publishing Associates/Cornell University Press; 2004. http:// www.cornellpress.cornell.edu/book/?GCOI=80140100664830

18. Higuchi DA, Almeida MC, Barros CC, Sanchez EF, Pesquero PR, Lang EA, et al. Leucurogin, a new recombinant disintegrin cloned from Bothrops leucurus (white-tailed-jararaca) with potent activity upon platelet aggregation and tumor growth. Toxicon. 2011;58(1):123-9.

19. Usami Y, Fujimura Y, Miura S, Shima H, Yoshida E, Yoshioka A, et al. A 28 kDa-protein with disintegrin-like structure (jararhagin-C) purified from Bothrops jararaca venom inhibits collagen- and ADP-induced platelet aggregation. Biochem Biophys Res Commun. 1994;201(1):331-9.

20. Masuda S, Maeda H, Miao JY, Hayashi H, Araki S. CDNA cloning and some additional peptide characterization of a single-chain vascular apoptosisinducing protein, VAP2. Endothelium. 2007;14(2):89-96.

21. Jia Y, Pérez JC. Molecular cloning and characterization of CDNAs encoding metalloproteinases from snake venom glands. Toxicon. 2010;55(2-3):462-9.

22. Paine MJ, Desmond HP, Theakston RD, Crampton JM. Purification, cloning, and molecular characterization of a high molecular weight hemorrhagic metalloprotease, jararhagin, from Bothrops jararaca venom. Insights into the disintegrin gene Family. J Biol Chem. 1992;267(32):22869-76.

23. Mandelbaum FR, Reichel AP, Assakura MT. Isolation and characterization of a proteolytic enzyme from the venom of the snake Bothrops jararaca (Jararaca). Toxicon. 1982;20(6):955-72.

24. Jia LG, Wang XM, Shannon JD, Bjarnason JB, Fox JW. Function of disintegrin-like/cysteine-rich domains of atrolysin A. Inhibition of platelet aggregation by recombinant protein and peptide antagonists. J Biol Chem. 1997;272(20):13094-102.

25. Serrano SM, Kim J, Wang D, Dragulev B, Shannon JD, Mann HH, et al. The cysteine-rich domain of snake venom metalloproteinases is a ligand for von Willebrand factor A domains: role in substrate targeting. J Biol Chem. 2006; 281(52):39746-56.

26. Pinto AF, Terra RM, Guimarães JA, Fox JW. Mapping von Willebrand factor A domain binding sites on a snake venom metalloproteinase cysteine-rich domain. Arch Biochem Biophys. 2007:457(1):41-6.

27. Fox JW, Serrano SM. Structural considerations of the snake venom metalloproteinases, key members of the $\mathrm{M} 12$ reprolysin family of metalloproteinases. Toxicon. 2005;45(8):969-85.

28. Fujimura S, Oshikawa K, Terada S, Kimoto E. Primary structure and autoproteolysis of brevilysin $\mathrm{H} 6$ from the venom of Gloydius halys brevicaudus. J Biochem. 2000;128(2):167-73.

29. Zang J, Zhu Z, Yu Y, Teng M, Niu L, Huang Q, et al. Purification, partial characterization and crystallization of acucetin, a protein containing both disintegrin-like and cysteine-rich domains released by auto-proteolysis of a P-III-type metalloproteinase AaH-IV from Agkistrodon acutus venom. Acta Crystallogr D Biol Crystallogr. 2003;59(Pt 12):2310-2.

30. Oliveira AK, Paes Leme AF, Assakura MT, Menezes MC, Zelanis A, Tashima AK, et al. Simplified procedures for the isolation of HF3, bothropasin, disintegrin-like/cysteine-rich protein and a novel P-I metalloproteinase from Bothrops jararaca venom. Toxicon. 2009;53(7-8):797-801.

31. Petretski JH, Kanashiro MM, Rodrigues FR, Alves EW, Machado OL, Kipnis TL. Edema induction by the disintegrin-like/cysteine-rich domains from a Bothrops atrox hemorrhagin. Biochem Biophys Res Commun. 2000;276(1):29-34.

32. Wang WJ, Huang TF. Purification and characterization of a novel metalloproteinase, acurhagin, from Agkistrodon acutus venom. Thromb Haemost. 2002;87(4):641-50.

33. Yoshida S, Koike K. Chapter one - Lipid and Membrane Dynamics in Biological Tissues - Infrared Spectroscopic Studies. In: Iglic A, editor. Advances in Planar Lipid Bilayers and Liposomes. United States: Academic Press; 2011. p. 1-32

34. Barth A. The infrared absorption of amino acid side chains. Prog Biophys Mol Biol. 2000;74(3-5):141-73.

35. Dritsa V. In: Theophile T, editor. Infrared Spectroscopy - Life and Biomedical Sciences, InTech; 2012. doi:10.5772/2655.

36. Jagadeesan G, Kavitha AV, Subashini J. FT-IR Study of the influence of Tribulus terrestris on Mercury intoxicated mice, Mus musculus liver. Trop Biomed. 2005;22(1):15-22. 
37. Liu KZ, Xu M, Scott DA. Biomolecular characterisation of leucocytes by infrared spectroscopy. Br J Haematol. 2007;136(5):713-22.

38. Roque A, Ponte I, Suau P. Secondary structure of protamine in sperm nuclei: an infrared spectroscopy study. BMC Struct Biol. 2011:11:14.

39. Barth A, Haris PI. Biological and Biomedical Infrared Spectroscopy. Amsterdam: IOS Press BV; 2009.

40. Barčot O, Balarin M, Gamulin O, Ježek D, Romac P, Brnjas-Kraljević J. Investigation of spermatozoa and seminal plasma by fourier transform infrared spectroscopy. Appl Spectrosc. 2007;61(3):309-13.

41. Dai J, Liu J, Deng Y, Smith TM, Lu M. Structure and protein design of a human platelet function inhibitor. Cell. 2004;116(5):649-59.

42. Díaz A, Saxena V, González J, David A, Casañas B, Carpenter C, et al. Zirconium phosphate nano-platelets: a novel platform for drug delivery in cancer therapy. Chem Commun (Camb). 2012;48(12):1754-6.

43. Redfern DA, Gericke A. Domain formation in phosphatidylinositol monophosphate/phosphatidylcholine mixed vesicles. Biophys J. 2004; 86(5):2980-92.

44. Morris MD, Finney WF. Recent developments in Raman and infrared spectroscopy and imaging of bone tissue. Spectroscopy. 2004;18(2):155-9.

45. Wolkers WF, Walker NJ, Tablin F, Crowe JH. Human platelets loaded with trehalose survive freeze-drying. Cryobiology. 2001;42(2):79-87.

46. Liu KZ, Bose R, Mantsch HH. Infrared spectroscopic study of diabetic platelets. Vib Spectrosc. 2002;28(1):131-6.

\section{Submit your next manuscript to BioMed Central} and we will help you at every step:

- We accept pre-submission inquiries

- Our selector tool helps you to find the most relevant journal

- We provide round the clock customer support

- Convenient online submission

- Thorough peer review

- Inclusion in PubMed and all major indexing services

- Maximum visibility for your research

Submit your manuscript at www.biomedcentral.com/submit 